\title{
Normatividade da cooperação em aulas de teatro
}

\section{Normativity of cooperation in theater classes}

André Luiz Lopes Magela ${ }^{1}$ 


\section{Resumo}

Este artigo propõe a distinção e tratamento pedagógico, no planejamento e condução de aulas de teatro em escolas, de elementos de normatividade atuantes nas práticas de exercícios e jogos teatrais, particularmente nas situações em que a cooperação e a atenção conjunta operam. As intenções iniciais desta abordagem são o incremento da qualidade investigativa destas aulas, com consequente melhoria na especificação dos conteúdos trabalhados, e a constituição de ações de resistência e respostas concretas para alguns argumentos presentes em propostas politicamente reacionárias no Brasil, mais atuantes a partir do ano de 2016 e consolidadas nas eleições de 2018.

Palavras-chave: Educação teatral; política; normatividade; cooperação; atenção conjunta
Abstract

This article proposes the distinction and pedagogical treatment, in the planning and conduction of theater classes in schools, of elements of normativity acting in the practice of theatrical exercises and games, particularly in situations where joint attention and cooperation operate. The initial intentions of this approach are to increase the investigative quality of these classes, with consequent improvement in the specification of the contents worked, and the constitution of resistance actions and concrete answers to some argumentative elements present in politically reactionary proposals in Brazil, more active since the year of 2016 and consolidated in the 2018 elections.

Keywords: Theater education; politics; normativity; cooperation; joint attention

E-ISSN: 2358.6958

Professor doutor, Universidade Federal de São João del Rei, Departamento de Artes Cênicas e PPGAC - Programa de Pós-Graduação em Artes Cênicas. Educação Teatral. CNPq é a agência de fomento desta pesquisa. andremagela@ufsj.edu.br 
Ordem é progresso

Michel Temer Folha de São Paulo, 01 de março de 2018

\section{Contexto}

A ascensão de Michel Temer à presidência do Brasil, em abril de 2016, foi a confluência de muitos processos políticos, tanto de reatividade aos governos do Partido dos Trabalhadores, o PT, quanto de levante exacerbado de influências sociais arraigadas no país. Em 2018, a eleição de Jair Bolsonaro com, até então, inesperados $55 \%$ dos votos válidos (sem contar os nulos e brancos, que podem ser vistos como sintoma de não desaprovação a suas propostas) consolida estas forças e um caráter reacionário em preferências políticas da maior parte da população brasileira.

Esta conjuntura é bastante complexa, e o escopo principal desse artigo não é examiná-la. Sobre esta matéria, já há algumas análises que têm revisado os modelos de interpretação da política do país. De modo tão urgente quanto prolífico, Vladimir Safatle (2015) (2016) (2018), filósofo e professor da Universidade de São Paulo - USP, vem caracterizando este momento como de embate entre modos de vida e de sentir conflitantes e excludentes. Não é a lógica convencional que nos auxiliará a lidar com estes acontecimentos, muito menos a resolver suas consequências.

Safatle, paradoxalmente, com esta definição dá conta do espanto quanto ao fato de que tantas pessoas aderiram, ao menos pelo voto, a posicionamentos indefensáveis - racismo, homofobia, defesa da tortura, armamento facilitado (crianças incluídas)... Mas o mais importante é que sua colocação nos alerta sobre qual é o campo de batalha para nossos esforços combativos - os afetos, e não a argumentação. A micropolítica perpetrada por aqueles que discutiam votos oferecendo café e bolo nas ruas, dias antes do segundo turno das eleições, concretizou bem este tipo de luta. E é oportuno adiantar que Safatle também indiretamente nos indica como as artes, e aulas que as abordem, podem ser um centro de atuação política neste momento, uma vez que elas manejam aquilo que está efetivamente em jogo: o que é da ordem do sensível, e não do estritamente racional.

Mas, ao mesmo tempo, argumentos também são um modo de enfrentar a atual situação, um modo de oferecer resistência. Principalmente se desconstroem as alegações que são utilizadas por forças reacionárias para justificar suas ações.

O combate à corrupção imputada ao Partido dos Trabalhadores foi o motivo exposto pela maioria daqueles que, mesmo sem adotar explicitamente os valores repreensíveis da campanha vitoriosa de 2018, rejeitavam, no segundo turno destas eleições, a alternativa disponível para que Bolsonaro não alcançasse a presidência votar em Fernando Haddad / PT. Mas se ampliarmos o olhar para esta esfera conexa à corrupção, podemos notar que, mesmo antes de 2016, os argumentos mais utilizados pelos atores sociais deste processo afinam-se a promessas de austeridade, de ordem, de segurança.

Estes valores, por mais que hoje detectemos borramentos destas fronteiras conceituais, ainda têm sido assumidos em termos de posicionamentos de direita e 
de esquerda. Neste imaginário, à direita se aliariam o correto, o ordenado, o rigor, o trabalho. Joesley Batista, em carta pública, finaliza seu pedido de desculpas com a autoidolatria "enfrentaremos esse difícil momento com humildade e o superaremos acordando cedo e trabalhando muito" (Batista, 2017). A referência aos "vagabundos", "mortadelas", e a equivocada associação do sucesso profissional dos ricos ao seu trabalho e mérito pessoal (Pluchino, Biondo, Rapisarda, 2018) são outras aparições desta concepção.

Em oposição, à esquerda e aos campos sociais que lhe são agregados (as humanidades, as artes), estariam irmanados a desordem, o caos, a insegurança, a preguiça. As repetidas ideias legislativas de Thiago Turetti (Brasil, 2018), um dos mais ativos militantes de Bolsonaro na Internet, para que sejam extintos cursos de humanidades nas universidades públicas para "direcionar esses investimentos a cursos mais sérios, por exemplo, medicina ou engenharia", e as ações do governo Bolsonaro relativas à educação e à cultura atestam esta afirmação.

Talvez, mais do que por uma opção política ou ideológica, a adesão aos valores que desde 2016 não mais se recalcaram no Brasil se dá pela crença de que a promessa de ordem propalada pelos reacionários é verdadeira. Que a vida seria mais garantida e melhor vicejaria se adotarmos os valores da direita. Promessa de harmonia e manutenção da vida pelo estrito acatamento às leis, normas e regras já instituídas; pela segurança de andar na linha, se seguir o certo que é previamente definido sem contradições.

\section{Real política}

A esta fórmula de esperança, Jacques Rancière (2012) confere a designação de "policial": acatar e manter a ordem vigente de perceber e partilhar o mundo. $\mathrm{O}$ "policial" se distingue, por oposição, daquilo que Rancière define como "política":

Arte e política têm a ver uma com a outra como formas de dissenso, operações de reconfiguração da experiência comum do sensível. Há uma estética da política no sentido de que os atos de subjetivação política redefinem o que é visível, o que se pode dizer dele e que sujeitos são capazes de fazê-lo. Há uma política da estética no sentido de que as novas formas de circulação da palavra, de exposição do visível e de produção dos afetos determinam capacidades novas, em ruptura com a antiga configuração do possível. (Rancière, 2012, p.63)

O conteúdo ideológico do "policial" é escamoteado, ofuscado por sua faceta já instituída (a única mostrada), uma vez que sua política, seus modos de partilha do sensível, já foi previamente estabelecida. A arrogação de verdade das ciências naturais e exatas e a naturalização dos modos capitalísticos de relação (Rolnik, 2018, p. 103) atestam esta omissão: ambos se pretendem apolíticos e não ideológicos. Mas o que realmente ocorre é que suas políticas (seus processos de configuração) são apartadas de nosso domínio de percepção e intervenção.

A este modo "policial" é atribuído o poder de responder às necessidades da vida convencionadas como concretas - habitação, comida, proteção... Decorre disto, em grande parte, seu poder de conquistar, principalmente em momentos de crise, uma 
dependência que exclui outras formas de relação com o mundo (a assumidamente artística e filosófica, por exemplo). Em suma: o grande argumento que temos ouvido é que estas formas policiescas de relação e percepção do mundo é que são importantes, e a arte e as humanidades são supérfluas.

Este tem sido historicamente o maior argumento contra a prática e o ensino de humanidades e artes em escolas para todos: sua inutilidade e o prejuízo que causam à ordem. Mas os últimos fatos confirmam o que talvez já saibamos: nada está mais distante da realidade. A peculiar incompetência que já se anunciava como característica do atual governo ${ }^{2}$ o atesta, mas podemos estender esta análise para todas as formas de austeridade superficial presentes na vida. Esta promessa da direita não se cumpre, em pelo menos duas dimensões.

Primeiro: esta forma convencional de conservadorismo não é garantia de meIhor viver; e, em última instância, o que ela pode garantir é uma "morte em vida" (Kastrup, 2008, p. 62). Todos os seus efeitos colaterais (desigualdade social, a redução do enriquecimento da subjetividade à promoção do "capital humano", utilização irresponsável de recursos) já seriam suficientes para se questionar esta perspectiva convencional. Mas o ponto crucial é que a adoção destes valores "policiais", eminentemente restritos à obediência e à segurança, é uma opção equivocada, na medida em que rejeita o que talvez seja o mais importante na vida: a construção de uma vida bela, a promoção de uma "estética da existência" (Foucault, 2010). É por beleza, por uma vida teatralmente bela (Magela, 2018, p. 304-305), e não por comida e abrigo, que devemos viver

O segundo lugar em que não se cumpre a promessa da direita de garantir a ordem, é o fato de que o questionamento das formas vigentes, leia-se fazer filosofia e arte, não é causa de anomia e caos social. Da mesma maneira, o regime "policial" não é o que produz a ordem; ele apenas mantém, quase sempre de modo insustentável, uma ordem que foi previamente definida. De forma mais direcionada ao nosso campo de trabalho, o estético educacional, sabemos que na invenção artística, pedagógica ou não, o rigor, a regra, e mesmo a honesta austeridade, são condições essenciais para que o que importa aconteça - a efetiva política, aliada à construção de formas de viver partilhadas no mundo.

Como nota Erika Fischer-Lichte, ao abordar o quanto a performance Lips of Thomas, criada e conduzida por Marina Abramovic em 1975, perturbou os enquadres e normas estabelecidos para os modos de agir da plateia - "Que regras devem ser aplicadas aqui?" (Fischer-Lichte, 2008, p. 12) -, a arte, se potente, indaga aquilo que está instituído, para que se institua o novo. E se não o faz, se não fomenta, por vezes dolorosamente, a invenção de regras, isto é um problema (Schechner, 2012).

Ideia aqui defendida, mais adiante com exemplos concretos, o ensino de artes nos prepara para a vida (principalmente a política) e para os confrontos implicados nesta, e não para apenas obedecer.

\footnotetext{
2 Podemos destacar a ostensiva demonstração de ignorância de Jair Bolsonaro sobre questões básicas de gestão de um Estado, bem como as designações flagrantemente ideológicas dos responsáveis para cargos importantes da Administração Federal.
} 


\section{Estratégia epistemológica}

A proposta aqui construída, principalmente no que cabe às aulas de teatro em escolas, é atrelarmos o âmbito das necessidades e normas ao da experiência estética. Implicada nesta junção, está a aproximação da arte com o cotidiano, o que Alain Kerlan, filósofo da educação estética, considera a tarefa fundamental de um processo de democratização cultural: "restaurar a continuidade entre a experiência estética e os processos normais da existência" (Kerlan, 2015, p. 276).

Contra as ações de descrédito das aulas de artes, proponho uma resistência, no sentido de valermo-nos das mesmas armas que as forças reacionárias. Rebatermos o argumento de que as artes não promovem a ordem, mostrando que sim: elas não só promovem a ordem, como são a própria base da criação e sustentação dinâmica das ordens, normas, regras.

Em outras palavras: a operação de constituição normativa é eminentemente estética, uma vez que envolve a configuração, a composição de mundos (Kerlan, 2017, p. 215). Por sua vez, a prática estética cria e aprimora a política; ensina a lidar com normas, também as inventando:

O que nos falta é rigor. Sim, rigor: a mais estranha de todas as paixões, esta que queima e constrói. Nenhuma verdadeira construção se ergueu sem essa impressionante crueldade de artista que se volta contra si mesmo até produzir dos seus próprios desejos a plasticidade do que faz nascer de si toda forma. Só a verdadeira disciplina, esta que não é repressão ou submissão da minha vontade à vontade de um outro, mas que é trabalho sobre si, que é produção de uma revolução na sensibilidade, salva. Uma disciplina de artista. É ela que falta à nossa política. (Safatle, 2016, p. 29)

Há muitos estudos recentes que expõem como ainda é necessário justificar-se, para a sociedade como um todo, o ensino de artes em escolas, por exemplo (Fourreau, 2018) (Bamford, 2009) (Choquet, Kerlan, 2016). Entretanto, ainda há (compreensivelmente) precariedades nos modos de enfrentamento desse problema. Uma destas dificuldades reside nos tipos de benefícios que aulas de artes ofereceriam a seus participantes. Diferentemente do que o senso comum professa (e aqui estão incluídos artistas e professores de artes), defendo que mostremos para a sociedade que o ensino de artes, mais do que benefícios por vezes acessórios, está associado ao que é mais atuante na sobrevivência.

Não me refiro à arte instituída, que não necessariamente realiza isto, muito menos aos artistas; mas à "função artista", a arte enquanto operação, acontecimento, vista de modo intensivo: "É o que Nietzsche descobria como operação artista da vontade de potência, a invenção de novas 'possibilidades de vida' " (Deleuze, 1992, p. 123). A distinção aqui não se dá entre artistas, enquanto pessoas especiais, e o resto da população; mas na percepção de uma arte intensiva operando nos acontecimentos. E uma educação que fomente que isto ocorra e/ou seja ampliado.

Esta operação toca os modos de lidarmos com as configurações da percepção cotidiana, praticando a construção dinâmica de rigores e normas, bem como permitindo a melhor percepção das normas instituídas, com as quais temos de negociar a cada segundo. 


\section{Dimensão normativa}

A normatividade é condição para a ocorrência de todas as nossas ações, e é pesquisada em vários campos de conhecimento. A elaboração do conceito de frame (quadro) ou framing (enquadre) (Bateson, 1954) (Goffman, 1974), utilizado de modos distintos pelo linguista George Lakoff (2004) e pela filósofa Judith Butler (2016), exemplifica estes estudos. Menos do que um corpus de regras e normas, a normatividade consiste em processos dinâmicos e inventivos, que precisam ser considerados como tal, diferentemente às concepções que consideram normas como algo estático a ser obedecido. Se adotamos na educação teatral abordagens contemporâneas e filosoficamente ancoradas, isto nos permite perceber a normatividade como dispositivo para a construção de melhores relações na sociedade:

Meu argumento [...] não é paralisar o julgamento ou minar as pretensões normativas, mas sim insistir que devemos formular novas constelações para pensar a normatividade, se quisermos proceder de maneiras intelectualmente abertas e compreensivas a fim de compreender ${ }^{3}$ e avaliar o mundo em que vivemos. (Butler, 2016, 207)

A normatividade, em termos direcionados para este artigo, pode ser tomada como situações de instituição, entre indivíduos, de planos comuns de conhecimento e de trato dinâmico com o estabelecido. Ou, de modo mais abrangente:

A normatividade refere-se à nossa capacidade de discriminar entre respostas apropriadas e não apropriadas aos estímulos, e à capacidade de avaliar criticamente e revisar os padrões que regulam as formas de conduta nas quais expressamos esse senso de adequação. Mas refere-se também à nossa capacidade de agir de acordo com tais avaliações e, em particular, de agir de maneira a abordar diretamente as ordens normativas que governam nossas vidas ${ }^{4}$. (Frega, 2015, p.1)

Articulando o sabido com o novo, e o fixo com o mutável, a normatividade proporciona a mediação intersubjetiva para a invenção de novos modos de viver, âmbito onde a arte e a filosofia assumem papel primordial. Se, por um lado, a arte depende do estabelecido para ser erigida, ela também desestabiliza o estabelecido, como bem faz a filosofia.

Alain Kerlan, abordando a importância da normatividade nas artes (e a arte como constitutiva da normatividade do cotidiano), ao notar que o "indivíduo não se considera mais apenas sujeito às normas, mas também fonte de normas", nos indaga: "Como articular criatividade e normatividade?" (Kerlan, 2015, p. 277). Uma das ações da arte é reconfigurar a normatividade já presente na vida em termos não apenas representativos, mas majoritariamente criando suas normatividades e vidas autônomas, que ampliam, recortam, questionam e enriquecem o real. Esta reconfiguração

\footnotetext{
3 No original, "grasp", que pode também ser traduzido por "apreender".

4 Normativity refers to our capacity to discriminate between appropriate and non-appropriate responses to stimuli and to the capacity to critically appraise and revise the patterns that regulate those forms of conduct in which we express this sense of appropriateness. But it refers also to our capacity to act in accordance with such appraisals, and in particular to act in ways that address directly the normative orders which govern our lives. (Tradução nossa)
} 
não se dá apenas nos locais previamente destinados para a prática artística profissional (museus, locais de espetáculos etc.); ela pode e deve constituir o cotidiano, desde as ações mais práticas até os momentos mais sofisticados - sempre quando a percepção, com seu caráter estético, esteja em jogo.

\section{O básico é requintado}

Tomemos como exemplo privilegiado, para embasar esta afirmação, a cooperação. Esta instância intersubjetiva, que constitui o substrato mais sólido das redes que permitem que vivamos, é composta eminentemente por elementos de atenção organizados esteticamente. Ela é um destes elementos constitutivos da vida, no que concerne, por um lado, à sobrevivência mais estrita, e por outro à produção de momentos e modos de viver potentes e/ou excepcionais.

A cooperação é uma instância capital na nossa existência, como sustenta Michael Tomasello (2016), que discrimina meticulosamente as operações cognitivas envolvidas nessa atividade que é eminentemente humana, e elemento chave para a construção da cultura. Segundo pesquisas desenvolvidas nos últimos vinte anos por Tomasello (1999) (2019), que encontram ressonância em trabalhos como o dos economistas Samuel Bowles e Herbert Gintis (2011), a capacidade de cooperação é o que mais distintamente nos diferenciaria de todos os outros primatas, e foi o que permitiu à humanidade chegar aos conhecimentos e habilidades que apenas um indivíduo não consegue atingir, já que a cultura se compõe de redes cognitivas que, em conjunto, constituem um processo de coordenação social.

Tais atos de pensamento são formados por situações comunicativas simples, elementares como, por exemplo, "perspectivação"5, "conhecimento do próprio papel (função) e dos papeis de outros" e "perceber a relevância" de fatos para outros, inverter papeis e simular como os outros avaliam seus parceiros (Tomasello, 2016, p.144). De todos estes elementos, a "atenção conjunta" - perceber que outra pessoa percebe algo que eu percebo - é a capacidade cognitiva fundamental para que todas estas outras ocorram. Sempre em diálogo com instâncias de normatividade, a atenção conjunta se articula com o "comprometimento conjunto" (Carassa et al., 2008), também abordado nos estudos da cognição e da aprendizagem:

[...] trata-se de uma configuração para o relacionamento entre as pessoas definida pelo fato de que os interactantes devem estabelecer de forma mútua, mas não necessariamente equivalente, obrigações e direitos que regulamentam as relações que contrataram entre si. O comprometimento conjunto se constrói num contexto específico e se desenvolve mediante objetivos também específicos, de forma tal que, ao tratarmos dele, chegaremos necessariamente à sua natureza, além de normativa, também situada. (Gerhardt, 2014, 892)

A atenção conjunta é que permite um "chão comum" (situações que tacitamente são conhecidas ou estabelecidas pelos envolvidos), a percepção de que se está

\footnotetext{
5 Os termos em aspas nestes parágrafos são elementos analisados por Tomasello, colhidos dos livros, citados, mas localizados esparsamente em muitas páginas destes livros e reunidos de maneira minimamente organizada para a exposição deste artigo.
} 
sendo avaliado por outros, e o "auto-monitoramento", que torna o nós maior do que o eu, formando uma "racionalidade cooperativa", "no sentido de que cada parceiro abdica livremente de algum controle pessoal sobre suas ações, em benefício da agência comum na qual ele é uma parte constitutiva" (Tomasello, 2016, p.145). Esses componentes desembocam em uma "mentalidade de grupo", que permite realizações coletivas, em co-dependência, com cada participante vendo as preocupações e objetivos de outros da mesma maneira como vê as suas (ibidem, p.147).

E estes atos cognitivos estão presentes de modo privilegiado em aulas de teatro. O que se argumenta de modo central neste artigo é a importância de se assumir esta característica das aulas de teatro, para explicitá-la e intensificar seu poder de ampliar a cooperação nas interações intersubjetivas dos alunos em sua vida cotidiana.

Esta abordagem se propõe como eficaz politicamente; ou ao menos de resistência. Inicialmente, por situar-se no campo de batalha identificado por Vladimir Safatle - o dos afetos e modos de sentir. E, em segundo, por deslocar os quadros de avaliação e de valorização da educação teatral para um campo que foi tomado pelas forças políticas hegemônicas - o da ordem, da norma, da regra, da produção de formas de viver que deem conta das nossas necessidades essenciais (estando a beleza de viver incluída nesta categoria).

\section{Práticas de atenção coletiva}

Ilustro esta articulação conceitual com três exemplos bastante concretos. Analisarei três exercícios bastante conhecidos e utilizados em aulas de teatro, identificando a presença dos elementos cognitivos colocados em relevo neste artigo. E proponho, através deste direcionamento de olhar, implicações pedagógicas e políticas que podem ocorrer na condução e prática direcionadas destes exercícios.

Examinemos uma atividade muito utilizada no início de oficinas de teatro como modo de apresentação dos participantes. Todos ficam em roda, e o condutor propõe as regras do jogo: ele diz seu nome, olha para alguém e se dirige lentamente ao local onde essa pessoa está. Esta, por sua vez, tem de fazer o mesmo (dizer seu nome, olhar para alguém e ir ocupar seu lugar), deslocando-se antes que seu lugar seja ocupado. Esta "bola imaginária" (a transmissão de ação pela sequência nome-olhar-deslocamento) vai sendo jogada até que todos tenham dito seu nome várias vezes. O condutor interrompe a "bola", instruindo que agora cada um falará o nome daquele cujo lugar ocupará. A atividade é realizada com esta mudança, até que todos os nomes sejam também falados várias vezes. Após isto, a nova instrução elimina a fala, e é nesse momento que, na perspectiva deste artigo, o exercício fica realmente interessante...

Com todos calados e em roda, o condutor olha fixamente para alguém e vai para seu lugar (trocas de sinais ou gestos comunicativos não são permitidos - se alguém olha fixamente para mim, é apenas porque vai fazer a ação inequívoca de tomar meu lugar). Essa pessoa, de modo ágil, mas não afobado (o tempo e o ritmo são a tessitura do jogo; e da vida), olha para outra pessoa e vai ocupar o seu lugar; e assim a bola vai passando pelas pessoas.

O condutor, quando este processo mudo se consolida, sem interromper a ati- 
vidade cria outra "bola", olhando para alguém e indo ocupar seu lugar quando já há a primeira bola (apenas o condutor - o professor ou algum aluno designado como condutor - começa e termina as bolas). Com um grupo de quinze pessoas, cinco bolas talvez possam estar ativas, se as trocas funcionarem bem.

Note-se que quando há uma bola todos sabem para onde olhar. Mas quando esse número aumenta todos têm de ficar bem atentos, porque a qualquer momento alguém pode estar olhando para você, querendo seu lugar e convocando-o a trabalhar.

O trabalho inicialmente é bem normativo, no sentido convencional: você deve apenas fazer o que a regra determina, sem nenhuma margem para invenção. Porém, quando há várias bolas, algumas estratégias de solução de problemas têm de ser criadas, como por exemplo mudar de pessoa no meio de sua trajetória. Não são poucos os problemas, as soluções e as reflexões sobre normatividade que a prática deste exercício apresenta para os participantes.

O que ressalto neste exercício é como ele envolve, ainda que de maneira mais simples, a articulação de protocolos, acordos implícitos e éticas de relacionamento cooperativo - políticas de cooperação. O mais visível é a modulação da atenção: se com uma bola não há desculpas para não ter percebido que alguém olhou para você, quando as bolas se multiplicam a lida com a atenção fica mais complicada para todos. A clareza do que se faz entre as pessoas também é dificultada, mas deve ser o mais inequívoca o possível: se alguém me olha para tomar meu lugar, isso deve ficar claro (lembrando que trocas de sinais não são desejáveis: é o ritmo que importa - fazer nos quadros dinâmicos de tempo, e não a comunicação explícita). Eu, então, devo rapidamente fazer meu trabalho, procurando alguém; e não preciso mais olhar para aquele que está andando em minha direção - ele faz seu trabalho e eu faço o meu. Quando algo dá errado, por exemplo eu ir para o lugar de alguém e esta pessoa não me viu ou saiu por estímulo de outra pessoa, eu devo resolver o problema respeitando os modos de agir coletivos que percebo estar em vigor.

Um chão comum é estabelecido, e o ritmo das ações é a concretização dessas relações de confiança que, para serem honradas, dependem de detalhes técnicos bastante precisos e dinâmicos. $O$ "chão comum" - objetivos e atenção compartilhados, numa situação onde um participante recursivamente infere o que o outro infere sobre ele, em termos de conhecimento mútuo (Tomasello, 2014, p.38) - é a situação mais básica e frequente para agirmos cooperativamente com outros. E é também o cimento dos exercícios teatrais.

Nos jogos e exercícios com regras explícitas, sendo Viola Spolin (1982) uma grande sistematizadora destas atividades no ocidente, isto é pedagogicamente estabelecido justamente para consolidar a necessidade e a disposição de agir nestes termos. Outros exercícios mais variantes e as improvisações teatrais articulam a novidade e a dinâmica das relações com normas previamente estabelecidas e implícitas ou, o que é mais complexo, criadas dinamicamente durante a sessão de trabalho.

O chão comum diz respeito também a algo muito caro a todos nós que vivemos em sociedade: chegar junto, compor um mundo com o outro, ser parceiro. Trata-se de uma questão tão moral quanto prática. 
Ora, este é um recurso básico na atuação teatral, importante entre os atores em trabalho e entre estes e a plateia. Mais enfaticamente: conseguir compor um chão comum com outro é condição sine qua non na prática teatral e nos processos de contato com a plateia, ao se estabelecer uma sintonia de referências com o mínimo possível de explicitação. Que o enredo, por exemplo, seja percebido, mas respeitando as camadas inomináveis e inumeráveis de percepção que configuram a experiência estética; os jogos entre o sabido e o não sabido com os colegas de cena e o espectador.

\section{Pedra de toque}

Se neste exercício o professor enfoca apenas a aprendizagem de nomes para uma apresentação, o jogo pode se tornar bem limitado pedagogicamente. As apresentações são feitas, as pessoas podem até se divertir ou se descontrair (critério mais superficial de avaliação: se o aluno gostou, a aula foi boa...). Mas o aproveitamento da atividade como processo de aprendizagem e ampliação da percepção e da potência de vida teatral fica sob responsabilidade do acaso.

Se o condutor é um pouco mais cioso quanto à disciplina e às regras per se, pode ser que a organização mantida ative uma atenção diferenciada junto aos alunos.

Entretanto, se o docente sabe que a apresentação é necessária, mas ele se atenta para os conteúdos que a aula de teatro opera (Magela, 2018), ele cuidará da necessidade de apresentação, do conhecimento dos nomes, mas saberá que isto é superficial. Porque estará sempre vigilante para o que importa, tentando que o exercício seja realizado de modo que operações cognitivas teatrais significativas sejam realizadas. Seu olhar para as ações dos alunos terá como foco o pensamento corporal que estará ativo a cada momento. E, ao final da aula, momento classicamente reservado à avaliação, serão estes conteúdos que serão colocados em questão para um saber mais consciente, dialogando com cognições mais racionais, por parte dos alunos. Os conteúdos são as situações de atenção teatral, o pensamento teatral (Magela, 2018) mobilizado nas situações fomentadas pela proposta de aula. E este pensamento teatral está imbricado à capacidade de compor normatividade e ações de cooperação.

Mas é preciso enfatizar que, similarmente ao que Vladimir Safatle preconiza - que o campo de batalha é da ordem dos afetos - o processo pedagógico nas aulas de teatro se dá em um âmbito somático (Magela, 2017a). As transformações que ocorrem na atenção dos alunos, estes conteúdos, são da ordem do intensivo, do operacional - não é a cooperação como temática, mas sim abordada de modo prático, tecnicamente em seus elementos constitutivos: experiências corporais efetivas de cooperação.

Jogos cooperativos, por exemplo, podem ser performados sem que nenhuma operação cooperativa ocorra no sentido somático (que é o que importa pedagogicamente). É o operacional que se torna somático; os modos de ser, e não mensagens. Afetos e modos de sentir, e não argumentos. Reconfigurações de modos de viver. Esta é a transformação pessoal significativa em aulas de teatro, sua educação mais particular, específica. 


\section{Dança de pensamento teatral}

Outra situação pedagógica também pode proporcionar concepções mais diretas e visualizáveis para o leitor. Uma "dança de cadeiras" modificada, que tem similitudes com o exercício de troca de olhares e é uma complexificação deste. Neste exercício, o condutor da atividade propõe que todas as pessoas fiquem sentadas em cadeiras dispostas no meio da sala, com uma distância aproximada de 1,5m entre si e em diversos ângulos de direção. Há o mesmo número de cadeiras e pessoas. Uma das pessoas se levanta, deixando a cadeira vazia, e é distanciada da cadeira pelo condutor. A tarefa desta pessoa é tentar sentar-se em uma cadeira vazia, e todos os outros tem por missão impedir que essa pessoa se sente. E a maneira que elas têm para fazer isso é ocupando as cadeiras.

Este dispositivo acarreta pessoas se levantando e sentando, fazendo com que várias cadeiras fiquem vazias dinamicamente por todo o espaço. Eventualmente a pessoa consegue se sentar, e a pessoa que ficou em pé (ou, se houve parada do jogo, a que deixou isso acontecer) é que se torna a próxima pessoa que tentará se sentar, com os outros a impedindo.

Se o condutor propõe apenas estas instruções simples (impedir o outro de sentar-se através da ocupação da cadeira), sem colocar mais regras ou definir melhor o trabalho, é provável que nada aconteça, do ponto de vista de aprendizagem de atenção. O que costuma acontecer é que os participantes entram num jogo competitivo onde o único interesse é fazer com que a pessoa não se sente, a todo custo, em nenhuma cadeira. As pessoas correm, falam, riem, se empurram, ordenam verbal e racionalmente o que fazer, tratando aquele que está em pé como o "bobo".

Mas o jogo muda significativamente se algumas regras complementares são observadas, definindo um melhor pré-enquadramento de normatividade: ninguém pode correr, nem se movimentar rapidamente, todos só podem andar e se sentar em velocidade média para lenta; não pode também haver toque entre eles, o que ajuda a evitar a competição ao sentar-se. Uma vez que alguém se levante, não pode se sentar de volta na mesma cadeira. Outra instrução é que os participantes não podem falar ou trocar gestos ou olhares, ou estabelecer qualquer tipo de comunicação. $O$ elo entre eles é apenas a dinâmica de ocupação das cadeiras, e esse é o aspecto principal a ser notado aqui, tanto em relação a canais de contato intersubjetivo, como ao fomento de outras cognições alternativas à racional.

O que a experiência mostra é que, ao ser realizado o exercício com essas regras, os participantes têm condições ${ }^{6}$ de, gradativa e consistentemente, estabelecer um modo muito específico de coletivamente ocupar o espaço, compor o tempo e de estabelecer outras maneiras de compartilhar aquela missão de ocupar as cadeiras como um corpo só (a competição e a exclusão chegam a desaparecer). Uma verdadeira modulação do tempo, do espaço e do comportamento ocorre, com todos

\footnotetext{
6 Noto oportunamente que a palavra "condição" tem sentidos à primeira vista conflitantes. Por um lado, ela pode se referir a condições (recursos) para que algo se dê. Por outro, condições (delimitações) impostas a uma ação. Se percebemos a aula de teatro e a vida como processos de subjetivação (Revel, 2005), onde ser sujeito é imbricado a sujeitar-se, as questões de normatividade deslocam-se para um terreno mais complexo, onde pessoas reconhecem e inventam normas de modo imbricado e dinâmico.
} 
atentos e engajados, numa dinâmica intrincada, bem sofisticada. A pessoa desejante de sentar-se pode ser trocada sem que o jogo seja interrompido; se ela consegue sentar-se, os outros já se referem à pessoa que sobrou ou titubeou no fluxo da atividade - e essa troca é bastante arguta. O que antes poderia ser uma competição banal se torna agora um acontecimento, uma dança, um evento onde todos constroem um espaço-tempo através de percepções ativas de temporalidade, movimento, intenções, qualidade dos corpos, articulações entre normas e dinamismos.

Por muitos momentos, é indiscernível para o condutor (sendo um olhar de fora, que não está tão mobilizado naquela cognição) se há apenas uma pessoa a ser impedida de sentar-se (porque muitos se levantam ao mesmo tempo, cooperando sem combinar) e muito menos quem é a pessoa. O corpo coletivo compõe a situação com uma inteligência por vezes indecifrável para o olhar de fora, configurada principalmente nas lógicas corporais de como, quando e quem deixará ou ocupará uma determinada cadeira.

Pelas regras e pelo confronto dos atuantes com elas, é produzido um campo cognitivo teatral que salta aos olhos - uma articulação entre as normas explícitas e prévias como "chão comum", e a criação de outras normas e lógicas temporárias e locais (de quem é a responsabilidade de ocupar tal cadeira nesta situação em específico?, quantos e como terão de se mover neste momento?). As ações, mesmo que por vezes indecifráveis, se dão em visível atenção conjunta e cooperação, compondo a dinâmica interna do jogo. E aprender e ampliar isso não pode ser resolvido pela fala do professor, mas pela experiência pedagógica teatral do processo.

\section{Risco e aprendizagem - Aprendizagem do risco}

Talvez uma avaliação das ações destes participantes possa remeter à noção de affordance, a "relação específica de uso entre um objeto ou evento e um determinado animal" (Gibson \& Pick, 2000, 15), no sentido de que as ações em fluxo vão se encaixando no que ocorre, naquele coletivo de pessoas. De certo modo, podemos identificar affordances sucessivas em nossas ações com outros. Vamos agindo interativamente em atenção conjunta (eu e os outros percebendo o espaço e todas as ações), sempre combinando nossas ações com múltiplas camadas de possibilidades do que vai ocorrendo, numa complementariedade com o ambiente. Tomando Virginia Kastrup, em sua exposição sobre aprendizagem e cognição, onde entes, relações e ambientes sempre se coengendram: aquele que aprende se reinventa (Kastrup, 2007, 173). Estas aulas ampliam a capacidade inventiva de criar novos modos de agir coletivamente.

Considerando um exemplo bem simples e direto no exercício, em que conseguimos perceber claramente participantes saindo de uma cadeira já contando que um outro vai ocupá-la, o que fica em relevo é o modo como o exercício mobiliza processos decisórios baseados em percepções sutis do que ocorre, e onde não há garantias. Aquilo que eu faço como atuante sempre está baseado no que eu penso que os outros pensam, e nos conhecimentos prévios e dinâmicos entre as partes - mais uma vez, o chão comum, abordado por Michael Tomasello. Uma série de suposições do que o outro quer e está pensando, associadas a avaliar e assumir diversos riscos de agir com o outro, tomando os cuidados supostamente necessários. 
A procura por outras formas de viver não ameaça de forma necessariamente destrutiva a vida - ao contrário: seus riscos são necessários para que ela viceje. E a prudência necessária para experimentar estes riscos demanda uma cautela dinâmica:

[...] acautelar-se não significa seguir uma mera regra prática cujo uso pode ser generalizado e estendido a toda sorte de situação. Ter cautela é colocar-se numa atitude estratégica ao lidar com os outros corpos, é aprender a entrar em composição com eles, a extrair das oscilações afetivas que eles nos provocam um manejo da própria potência de afetar e ser afetado e, consequentemente, da potência de agir. (Silva, 2012, p.460)

Eu não ajo e apenas depois avalio: as duas coisas são realizadas ao mesmo tempo em diversas ordens de informações e suposições, com ajustes ininterruptos, articulando prudência e ousadia.

A diferença entre o exercício da cadeira, antes e depois das regras serem colocadas com cuidados pedagógicos relativos a aspectos de normatividade, é um exemplo cabal do discernimento aqui proposto entre uma aula ser de teatro, no sentido intensivo ou operativo do teatral, ou não. Se ela mobiliza cognitivamente, somaticamente, elementos teatrais ou não.

Como já exposto, aulas com as operações constitutivas da cooperação - não como tema, mas adotando uma tecnicização estética da cooperação. A cooperação como modo de sentir e partilhar o real - política, portanto. Da mesma maneira, uma pedagogia orientada pela função artista, pela arte como operação, vista de modo intensivo, acontecendo no aluno.

O cuidado com o fato de o exercício ativar ou não a atenção teatral, eminentemente conjunta, é que é significativo. A aposta é que esta ativação pode ter um efeito de ampliação da potência e autonomia do aluno nas dimensões teatrais que existem na vida de todos no cotidiano. Junção entre a aula e a vida, entre a sobrevivência e o estético.

\section{Ética na prática teatral educacional}

A arte constitui e investiga outros modos de lidar com regras e normas (implícitas ou explícitas, já existentes ou inventadas), e fomenta a invenção e a singularidade que podem surgir nesses modos. Nestes exemplos, em exercícios que predominantemente evitam (dispensam?) o amparo da fala, são colocadas em questão as aberturas e fechamentos, decisões, recusas e aceitações, que podem ser feitas sem comunicação ou predefinições, mas em regras e modos produzidas pelas relações de forças criadas por todos, e em relações com os fluxos dessas forças:

Trata-se de inventar modos de existência, segundo regras facultativas, capazes de resistir ao poder bem como se furtar ao saber, mesmo se o saber tenta penetrá-los e o poder tenta apropriar-se deles. Mas os modos de existência ou possibilidades se vida não cessam de se recriar, e surgem novos. (Deleuze; 1992, p. 116)

Esta ética de cena se transpõe numa ética de pensamento, uma atenção específica, uma percepção, ações: "[...] a ética é um conjunto de regras facultativas que avaliam o que fazemos, o que dizemos, em função do modo de existência que 
isso implica" (Deleuze; 1992, p.125). O que mais uma vez friso é que, uma vez que as ações são tomadas numa percepção e num processo de decisão que escape ao hegemonicamente comunicacional e ao racional, os atuantes alunos podem desmanchar convenções prévias de acordos e comportamentos, reconfigurando o âmbito dos processos decisórios.

Retomando o aspecto da sobrevivência: as regras propostas inicialmente e inventadas nestes exercícios não são do tipo "se fizer ganha", mas sim "se não fizer morre". Como no exercício de olhares, se as normas não servirem, todos perdem. Trata-se da aprendizagem de modos de reconhecer a realidade do poder e das forças atuantes (eventualmente inextricáveis para observadores) e produzir subjetividade singular com isto. Dominar esta instância, em jogo, visa menos trabalhar a obediência à instância policial do que ensinar a fazer política - fomentar a criação de modos coletivos que sejam viáveis, sobreviventes, funcionais e interessantes existencialmente. Uma resposta prática à falácia de que ser reacionário é a fórmula para se ser austero e prosperar.

Outros exercícios podem mobilizar esta arte de decidir dinâmica e coletivamente, como uma adaptação do exercício "hipnotismo colombiano" (Boal, 2000, 91), em que um atuante conduz a face de outro com sua mão. Nesse trabalho, podemos fazer uma série de variações gradativamente complexas, sem interrupções, mesmo que com trocas de duplas. Inicialmente, a mão de um conduz, com precisão e rigores (a manutenção da distância e do paralelismo entre a mão e a face), seu parceiro. Este é o exercício "clássico", como ensinado nos livros.

Da mão conduzindo a face, após algum tempo fazendo-se o exercício, segue- se para a mão conduzir o peito, o peito conduzir o peito e o corpo inteiro (ombros, tronco e bacia) conduzir o corpo inteiro do outro, sempre se atentando para que não se caia num exercício de espelho (Magela, 2017b, p. 55).

Nesse estágio, com a introdução de ambos conduzindo e sendo conduzidos de corpo inteiro ao mesmo tempo, a situação se torna bastante complexa. A precisão tem de ser mantida ferozmente, e, se isto é contemplado, as lacunas e impossibilidades de os dois conduzirem e serem conduzidos ao mesmo tempo, com a obrigação de se manter esse complexo canal de contato (que começou sendo apenas mão para a face, sempre sem o uso de troca de olhares ou gestos e fala), faz com que questões de normatividade, constituição de lógicas singulares, ajustes sem comunicação etc., sejam trabalhadas. A impossibilidade de obediência satisfatória da regra, mas com a obrigação de engajamento para segui-la, convoca a uma produção normativa que atenda às relações específicas provisórias criadas pelos dois alunos, entre eles.

Se o condutor propõe uma improvisação sem fala imediatamente em seguida, as interações corporais se darão melhor como operações cognitivas teatrais, conexas a agenciar e construir normatividades singulares e dinâmicas, não verbalizáveis (Magela, 2017b, p.55). Improvisações, principalmente as minimalistas e sem fala, podem ser um exercício profundo de atenção conjunta. Mas é necessário que o condutor não caia na tentação de focar e alimentar a criatividade mais imediata e convencional dos alunos, mas sim deter-se sobre o quanto eles conseguem compor com os colegas uma atenção cooperativa, episódios de atenção conjunta (tão interessantes para a sobrevivência material imediata como para a composição de campos estéticos sofisticados). A aula 
pode mobilizar, então, a percepção e invenção de regras, modos, outras relações, que deem conta das forças e formas em ação nos aspectos teatrais da vida.

A exposição desses princípios e conceitos articulados com exemplos pretende mostrar como essas perspectivas aqui elaboradas podem estar presentes de modo bastante exequível na escola. A aposta é fomentar uma atitude investigativa do professor em direção a quanto seus rigores e critérios tocam elementos de normatividade; no caso, em situações de cooperação. Isto pode ser realizado através da adoção de sistemas e exercícios já existentes ou da invenção de novos.

Retomando e resumindo ao extremo as considerações aqui tecidas, a realização do exercício com ou sem um cuidado para que ali ocorra um pensamento teatral pode ser o que determinará se a atividade fomentará ou não um efetivo trabalho de educação teatral, de ampliação da atenção do aluno a dimensões teatrais da vida, totalmente necessárias à sobrevivência de todos, em todos os níveis (Magela, 2018).

Alguns exercícios teatrais podem compor modos qualificados de lidar com essas regras, forças e poderes; modos de se comportar, operando na aula, que se transpõem para a vida do aluno. Um corpo mais potente para inventar pensamentos teatrais que lidem melhor com estratos teatrais instituídos na sociedade. O mais importante nestas aulas é que as questões sociais não sejam ditas ou explicadas, mas vividas, experienciadas afetivamente, intensivamente, transbordando para o cotidiano dos alunos. Uma prática pedagógica orientada para que o aluno, junto com outros, faça, resolva, invente, cada vez mais sofisticadamente - num proveito essencial para as relações entre todos e para a política.

\section{Referências}

BAMFORD, Anne. The WOW Factor - Global research compendium on the impact of the arts in education. Berlin: Waxmann, 2009.

BATESON, Gregory. A theory of play and fantasy. In: Steps to an ecology of mind. Chicago: University of Chicago Press. (2000) (1955) (1954)

BATISTA, Joesley. Erramos e pedimos desculpas. Folha de São Paulo, São Paulo, 18 mai. 2017.

BOAL, Augusto. Jogos para atores e não-atores. Rio de Janeiro: Civilização Brasileira, 2000.

BOWLES, Samuel \& GINTIS, Herbert. A cooperative species - Human reciprocity and its evolution. Princeton, New Jersey: Princeton University Press, 2011.

BRASIL. Propostas para extinguir ou manter cursos de humanas movimentam portal e-cidadania. Senado notícias, Brasília, 19 abr. 2018. Disponível em: https://www12. senado.leg.br/noticias/materias/2018/04/19/propostas-para-extinguir-ou-manter-cursos-de-humanas-movimentam-portal-e-cidadania

BUTLER, Judith. Quadros de Guerra - quando a vida é passível de luto? Rio de janeiro: Civilização Brasileira, 2016. 
CARASSA, Antonella; COLOMBETTI, Marco; MORGANTI, Francesca. The role of joint commitment in intersubjectivity. In: MORGANTI, Francesca; CARASSA, Antonella; RIVA, Giuseppe (Org.). Enacting Intersubjectivity: a cognitive and social perspective on the study of interactions. Amsterdam: IOS Press, 2008. P. 187-201. Disponível em: https://www.researchgate.net/publication/267594835_The_role_of_joint_commitment_in_intersubjectivity

CHOQUET, Céline \& KERLAN, Alain. L'art au collège: quels effets pour les eleves?. Thèse de Doctorat de L'Université de Lyon 2. 2016. Disponível em: http://theses.univ-lyon2.fr/documents/lyon2/2016/choquet_c\#p=18a=TH.1

DELEUZE, Gilles. Conversações: 1972 - 1990. São Paulo: Editora 34, 1992.

FISCHER-LICHTE, Erika. The transformative power of performance. London, New York: Routledge, 2008.

FOUCAULT, Michel. A hermenêutica do sujeito. São Paulo: Martins Fontes, 2010.

FOURREAU, Éric (Org.). L'Éducation artistique dans le monde - récits et enjeux. Toulouse : Éditions de l'attribut, 2018.

FREGA, Roberto. The normative structure of the ordinary. In: European Journal of Pragmatism and American Philosophy [online] VII-1. 2015. Disponível em: https:// journals.openedition.org/ejpap/370

GERHARDT, Ana Flávia L. M. Comprometimento conjunto, normatividade e situatividade entre os muros da escola. In: Educação \& Realidade, Porto Alegre, v. 39, n. 3, jul./ set. 2014, p. 887-906. Disponível em: http://www.ufrgs.br/edu_realidade.

GIBSON, Eleanor J. \& PICK, Anne D. An ecological approach to perceptual learning and development. Oxford: Oxford University Press, 2000.

GOFFMAN, Erving. Frame Analysis: An Essay on the Organization of. Experience. Cambridge, MA: Harvard University Press, 1974.

KASTRUP, Virginia. A invenção de si e do mundo - uma introdução do tempo e do coletivo no estudo da cognição. Belo Horizonte: Editora Autêntica, 2007.

KASTRUP, Virginia. Autopoiese e subjetividade: sobre o uso da noção de autopoiese por G. Deleuze e F. Guattari. In: KASTRUP, Virginia \& TEDESCO, Silvia \& PASSOS, Eduardo. Políticas da cognição. Porto Alegre: Sulina, 2008. 
KERLAN, Alain. A Experiência Estética, uma Nova Conquista Democrática. In: Revista Brasileira dos Estudos da presença, Porto Alegre, v.5, n.2, maio/ago, 2015, p.266-286. Disponível em: www.seer.ufrgs.br/presenca

KERLAN, Alain. Le métier d'enseigner - approches philosophiques. Nancy : PUN Éditions Universitaires de Lorraine, 2017.

LAKOFF, George. Don't think of an elephant! Know your values and frame the debate. White River Junction, Vermont: Chelsea Green Publishing Company, 2004.

MAGELA, André L. L.. Cognição teatral e educação. In: Rascunhos - Caminhos da pesquisa em artes cênicas. Uberlândia, v.5, n.3. dez. 2018. Disponível em: http://www. seer.ufu.br/index.php/rascunhos/article/view/43132

MAGELA, André L. L.. Afecções, exercícios, protopedagogias teatrais. In: Rascunhos Caminhos da pesquisa em artes cênicas. Uberlândia, v.4, n.4. 2017b. Disponível em: http://www.seer.ufu.br/index.php/rascunhos/article/view/38729

MAGELA, André L. L.. Abordagem somática na educação teatral. In: Moringa - Artes do espetáculo. João Pessoa, v.8, n.1. 2017a. Disponível em: http://www.periodicos. ufpb.br/ojs/index.php/moringa/article/view/34856

PLUTINO, A.; BIONDO, A. E.; RAPISARDA, A.. Talent vs Luck: the role of randomness in success and failure. In: World Scientific. New York: Cornell University Press, 2018. Disponível em: https://arxiv.org/abs/1802.07068

RANCIĖRE, Jacques. O espectador emancipado. São Paulo: Martins Fontes, 2012.

REVEL, Judith. Foucault - conceitos essenciais. São Carlos: Editora Claraluz, 2005.

ROLNIK, Suely. Esferas da insurreição - notas para uma vida não cafetinada. São Paulo: n-1 Edições, 2018.

SAFATLE, Vladimir. O circuito dos afetos - corpos políticos, desamparo e o fim do indivíduo. São Paulo: Cosac Naify, 2015.

SAFATLE, Vladimir. Há um golpe militar em marcha no Brasil hoje. Intervenção em debate promovido pela Editora Boitempo em 24 de setembro de 2018. Disponível em: https://www.youtube.com/watch?v=BwLg13hSkRk

SAFATLE, Vladimir. Quando as ruas queimam: manifesto pela emergência. São Paulo: n-1 Edições, 2016. 
SCHECHNER, Richard. A vanguarda conservadora. In: Revista Brasileira de Estudos da Presença, Porto Alegre, v. 2, n. 2, jul./dez, 2012, p. 573-600. Disponível em: http:// www.seer.ufrgs.br/presenca.

SILVA, Cíntia Vieira da. Combater e compor: dilemas do agir em uma leitura deleuziana de Espinosa. In: Princípios - Revista de Filosofia. Natal, v. 19, n. 32 jul./dez. 2012, p. 457-481.

SPOLIN, Viola. Improvisação para o teatro. São Paulo: Perspectiva, 1982.

TEMER. Michel. Ordem é progresso. Coluna Opinião - tendências e debates. Folha de São Paulo, 01 de março de 2018. Disponível em: https://www1.folha.uol.com.br/ opiniao/2018/03/michel-temer-ordem-e-progresso.shtml

TOMASELLO, Michael. The Cultural Origins of Human Cognition. Cambridge, Massachusetts: Harvard University Press, 1999.

TOMASELLO, Michael. A natural history of human thinking. Cambridge, Massachusetts: Harvard University Press, 2014.

TOMASELLO, Michael. A natural history of human morality. Cambridge, Massachusetts: Harvard University Press, 2016.

TOMASELLO, Michael. Becoming Human: A Theory of Ontogeny. Cambridge, Massachusetts: Harvard University Press, 2019.

Recebido em: 15/11/2018

Aprovado em: 22/01/2019 